\title{
BEHAVIOR OF VITAL AND KILLED AUTOLOGOUS PERICARDIUM IN THE DESCENDING AORTA OF SHEEP
}

David T. Cheung, PhD

Suk Jung Choo, MD

Albert C. Grobe, MS

Douglas C. Marchion, MS

Hong He Luo, MD

David C. Pang, MS

Blaise E. Favara, MD

James H. Oury, MD

Carlos M. G. Duran, MD, PhD
Objectives: Cardiovascular implants of fresh autologous pericardium produced mixed results including fibrosis with retraction or thinning and dilatation. The reasons for these differences are unknown but may involve activation of cells intrinsic to the tissue implant. To better understand the behavior of autologous pericardial implants, we studied the outcomes of vital pericardium (fresh) versus ethanol-killed pericardium. Methods: Fresh and ethanol-killed autologous pericardium was transplanted as a patch, a conduit, or a rectangular flap bisecting the lumen in the descending aorta of sheep. The implants, recovered at 1,5 , 10, 15, and 30 days, were evaluated macroscopically and microscopically and by immunohistologic studies. Results: Fresh implants showed good preservation with fibrin deposition on day 15. Microscopically, cells positive for $\alpha$-actin and von Willebrand-related antigen appeared in the fibrin by day 10. By day 30 the flap was fibrotic and retracted whereas the patch and conduit retained their original appearance on the luminal aspect. An endothelium-like layer expressing von Willebrand-related antigen was present in the patch and conduit but absent in the flap. In contrast, the ethanol-killed implants were free of fibrin by day 10. By day 30, there were no signs of fibrosis or retraction, and a surface layer of cells expressing von Willebrand-related antigen, characteristic of endothelial cells, was present on all implants. All ethanol-killed implants were repopulated by host cells. Conclusion: The transluminal flap is an interesting model for studying the behavior of intraluminal autologous pericardial cardiovascular implants. Killing of the pericardial implants alleviated the fibrosis and tissue retraction observed with fresh flap implants. (J Thorac Cardiovasc Surg 1999; 118:998-1005)
$\mathrm{V}$ ital (fresh) autologous pericardium is a low cost biomaterial that has advantages for cardiovascular implantation. It is free of donor-derived pathogens, will not provoke an immune response, shows growth potential, and is easy to access. ${ }^{1-6}$ However, the use of fresh autologous pericardium as an implant has shown mixed results. The implants became fibrotic and retracted, ${ }^{7,8}$

From The International Heart Institute of Montana Foundation, St Patrick Hospital, 554 West Broadway, Missoula, Mont.

Received for publication Dec 22, 1998; revisions requested March 4, 1999; revisions received June 28, 1999; accepted for publication June 29, 1999.

Address for reprints: Carlos M. G. Duran, MD, PhD, The International Heart Institute of Montana Foundation, St Patrick Hospital, 554 West Broadway, Missoula, MT 59801 (E-mail: duran@montana.com).

Copyright (C) 1999 by Mosby, Inc.

$0022-5223 / 99 \$ 8.00+0 \quad \mathbf{1 2 / 1 / 1 0 1 2 0 2}$ exhibited progressive thinning with dilatation and aneurysm, ${ }^{5,9,10}$ or were incorporated into the host tissue. ${ }^{3-6}$ Retraction and fibrosis were observed when fresh pericardium was used as a patch or artificial chordae in heart valve reconstruction. , $^{7,11,12}$ The closure of large ventricular defects or patch reconstruction of the right ventricular outflow tract with distal pulmonary hypertension was reported to result in aneurysmal changes. ${ }^{5,9,10,13-16}$ In contrast, growth potential was documented in broad-based pedicled pericardial flaps implanted as atrial wall replacements or right-sided conduits in dogs and human beings in whom adequate blood supply was able to support tissue viability. ${ }^{3-5}$ The clinical use of fresh autologous pericardium in cardiovascular surgery is limited because of these uncertain outcomes. In an attempt to clarify this issue, fresh autologous pericardium containing living cells and the same tissue treated with $50 \%$ ethanol (ethanol-killed), which 


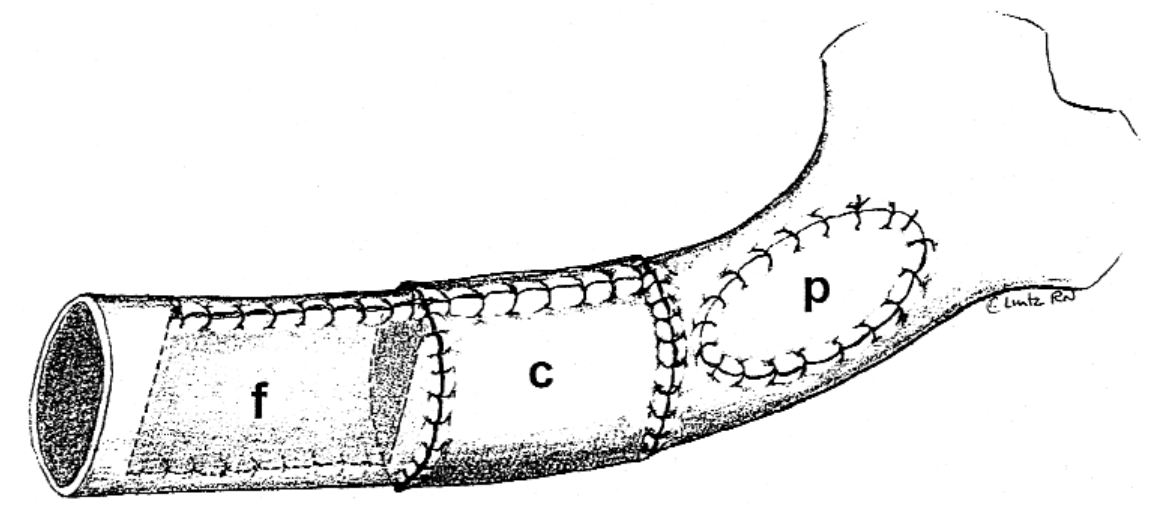

Fig 1. Configuration of autologous pericardial implants in the descending aorta of sheep. The pericardium was implanted as a patch $(p)$, conduit $(c)$, and flap $(f)$.

killed vital cells, were implanted in the descending thoracic aorta of sheep as a patch in the aortic wall, a conduit, and an intraluminal flap. Although the patch and the conduit implants were part of the aortic wall with the mesothelial surface contacting the blood, both surfaces of the intraluminal flap were exposed to blood, thus mimicking a heart valve leaflet. In this study, sequential analyses of the gross, microscopic, and immunohistochemical data were used to evaluate the behavior of this surgical biomaterial.

\section{Methods}

Fourteen Targhee sheep between 4 and 10 months old, 28 to $52 \mathrm{~kg}(36 \pm 7.6 \mathrm{~kg})$, were used. All animals were treated perioperatively with broad-spectrum antibiotics. General anesthesia was induced with ketamine $(1.0 \mathrm{mg} / \mathrm{kg})$ and propofol $(4.0 \mathrm{mg} / \mathrm{kg})$ intravenously and maintained with oxygen $(4 \mathrm{~L} / \mathrm{min})$, isoflurane gas $(1.5 \%$ to $2.5 \%)$, and half-bolus doses of propofol during the operation as needed. The chest wall was opened through the left 4 th intercostal space. The descending thoracic aorta was dissected and a 10-cm segment mobilized. A $6 \times 10-\mathrm{cm}$ rectangular piece of pericardium was harvested, with markers being placed to maintain the original craniocaudal pericardial orientation. For animals receiving ethanol-killed implants, the pericardial tissues were treated with $50 \%$ ethanol for 5 minutes and rinsed in phosphatebuffered saline solution (PBS).

A patch of approximately $1.5 \times 2 \mathrm{~cm}$ was resected from the harvested pericardium, followed by the construction of a 1.5 $\mathrm{cm}$ diameter $\times 2-\mathrm{cm}$ long conduit. The conduit was constructed by folding the pericardium with the mesothelial surface facing the lumen around a glass cylinder and suturing the free edges with a 5-0 polypropylene continuous running suture. Finally, a $1.5 \times 2-\mathrm{cm}$ segment was resected from the pericardium to be used as an intraluminal flap, bisecting the aorta. All these implants were oriented so that the craniocaudal direction of the pericardium was parallel to the aortic flow.
The descending thoracic aorta was isolated with crossclamps placed distal to the arch vessel (in sheep there is only 1 main vessel arising from the arch) and proximal to the takeoff of the first major intercostal or spinal artery. The animals were heparinized to maintain an accelerated clotting time above 300 seconds, after which an apicofemoral shunt was created to bypass the isolated segment of the descending thoracic aorta that received the implants. The patch was used to close a defect created in the aortic wall distal to the crossclamp with a continuous running 5-0 polypropylene suture. The patch was oriented with the mesothelial surface facing the aortic lumen. The aorta was transected distal to the implanted patch and incised longitudinally along its anterior margin for a distance of $2 \mathrm{~cm}$. One edge of the intraluminal flap was sutured to the aortic wall directly opposite the longitudinal incision and the opposite edge was sandwiched under tension between the walls of the aortic incision as the aorta was being closed with a continuous running 5-0 polypropylene suture. Finally, the pericardial conduit was positioned between the proximal and distal ends of the transected aorta with continuous running 5-0 polypropylene sutures (Fig 1). On completion of the operation, protamine was administered at 1.5 times the total heparin dosage with further adjustments determined by the accelerated clotting time. The chest was closed in layers and a chest tube was inserted. After extubation, the chest tube was removed and the animal transferred to its pen.

The control animals $(\mathrm{n}=1)$ for both the fresh and ethanolkilled groups were killed on day 1 . Subsequent animals were killed 5, 10, 15, and 30 days after the operation. The group with fresh tissue consisted of 2 animals per time point, and the group with ethanol-killed tissue consisted of 1 animal per time point. To prevent postmortem intraluminal clotting, the animals were fully heparinized (300U/kg) before being put to death. The sheep were killed with $1 \%$ propofol and $20 \mathrm{~mL}$ of potassium chloride (US Pharmacopeia $20 \mathrm{mEq} / \mathrm{mL}$ ) by injection. The descending aorta was harvested en bloc to include all 3 pericardial implants and a $1-\mathrm{cm}$ margin of normal aortic 

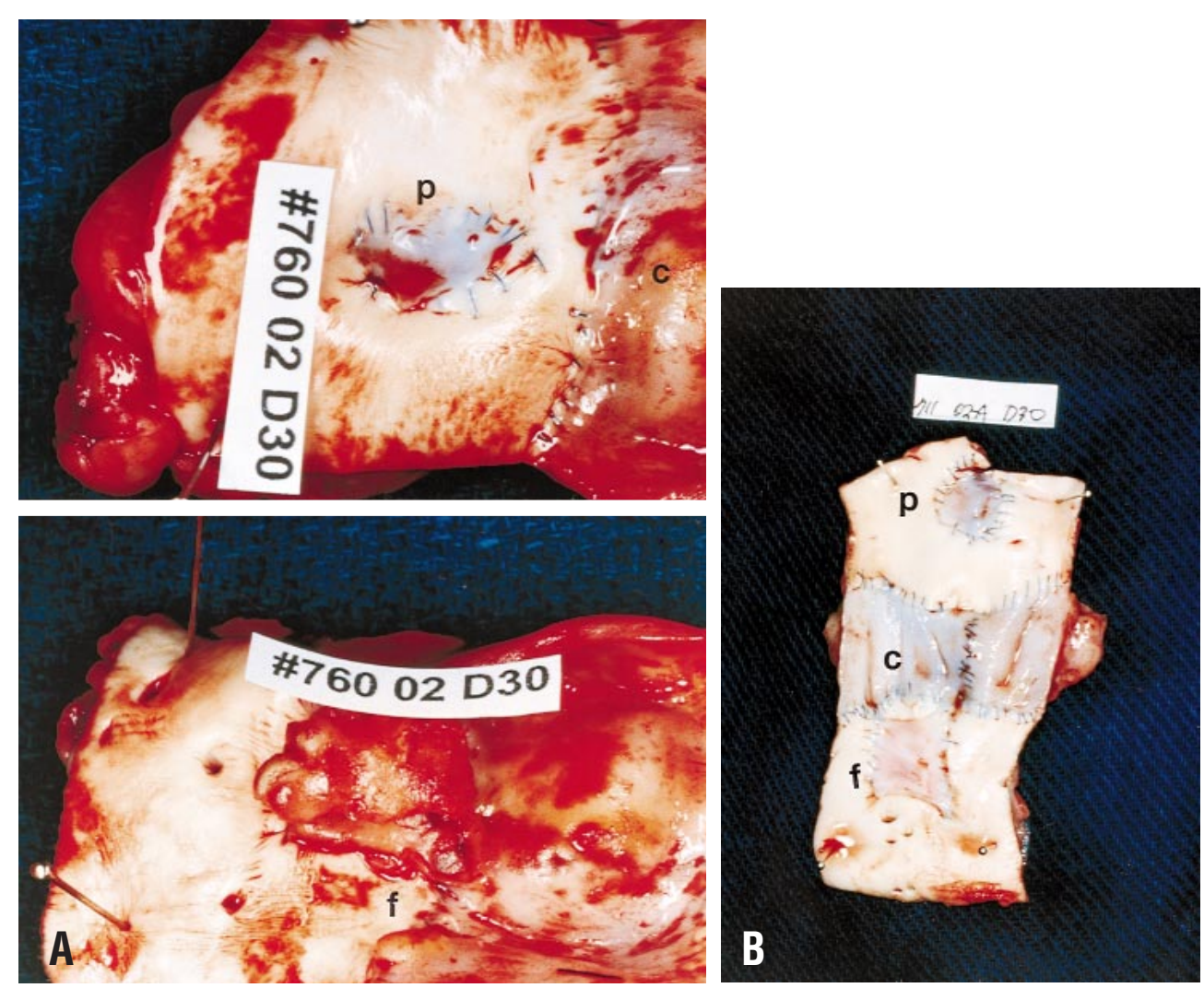

Fig 2. Gross histologic features of 30-day patch, conduit, and flap. A, The luminal aspect of the fresh patch $(p)$ and conduit $(c)$ remained smooth, whereas the flap $(f)$ was retracted and fibrotic. B, In contrast, the ethanol-killed patch $(p)$, conduit $(c)$, and flap $(f)$ were clean and smooth, showing no signs of fibrosis or retraction.

tissue. The aorta was split longitudinally for gross observation of the degree of fibrosis, dilatation or thinning, thickening, and retraction.

All animals were cared for in accordance with the "Principles of Laboratory Animal Care" formulated by the National Society of Medical Research and the "Guide for the Care and Use of Laboratory Animals" prepared by the Institute of Laboratory Animal Resources, National Research Council, and published by the National Academy Press, revised 1996. The use of the animals for this research was also reviewed and approved by the Institutional Animal Care and Use Committee (IACUC) of the University of Montana.

Histology. The specimens were fixed in Histo-Choice fixative (Amresco Inc, Solon, Ohio), embedded, and sectioned for histologic study. The patch and conduit were sectioned parallel to the direction of blood flow and included the junction between the implants and the aortic wall. Cross sections of the flap and aortic wall were made perpendicular to the blood flow to observe the aortic wall and edges of the flap. Sections were stained with hematoxylin and eosin, which stains nuclei blue and collagen pink, and Masson's trichrome, which stains collagen blue and muscle red.

Immunohistochemistry. Sections were cleared of paraffin and treated with $1 \%$ hydrogen peroxide in methyl alcohol for 30 minutes to remove endogenous peroxidases. The sections were blocked with $0.05 \%$ Tween-20 in phosphate buffered saline solution (PBS-T) for 30 minutes to prevent nonspecific antibody binding. The sections were incubated with either anti-smooth muscle cell $\alpha$-actin (clone 1A4) or anti-human von Willebrand-related antibodies for 30 minutes. Sections were then washed with PBS-T. The sections were incubated for 30 minutes with protein A-horseradish peroxidase. Sections were washed with PBS-T and visualized with the use of the horseradish peroxidase substrate DAB (Sigma Fast DAB, Sigma Chemical Co, St Louis, Mo). Horseradish peroxidase is an enzyme and, in the presence of hydrogen peroxide, converts DAB into an insoluble dark brown precipitate on the specimens. The development was stopped with water and the slides counterstained with hematoxylin and eosin. Controls included replacing either the antibody or protein Ahorseradish peroxidase with PBS-T followed by DAB development. Sections were probed for von Willebrand-related antigen, a known endothelial cell marker, and smooth muscle cell $\alpha$-actin, which is expressed in smooth muscle cells and myofibroblasts. The antibodies, protein A-horseradish peroxidase, Tween-20, and the DAB substrate were obtained from 

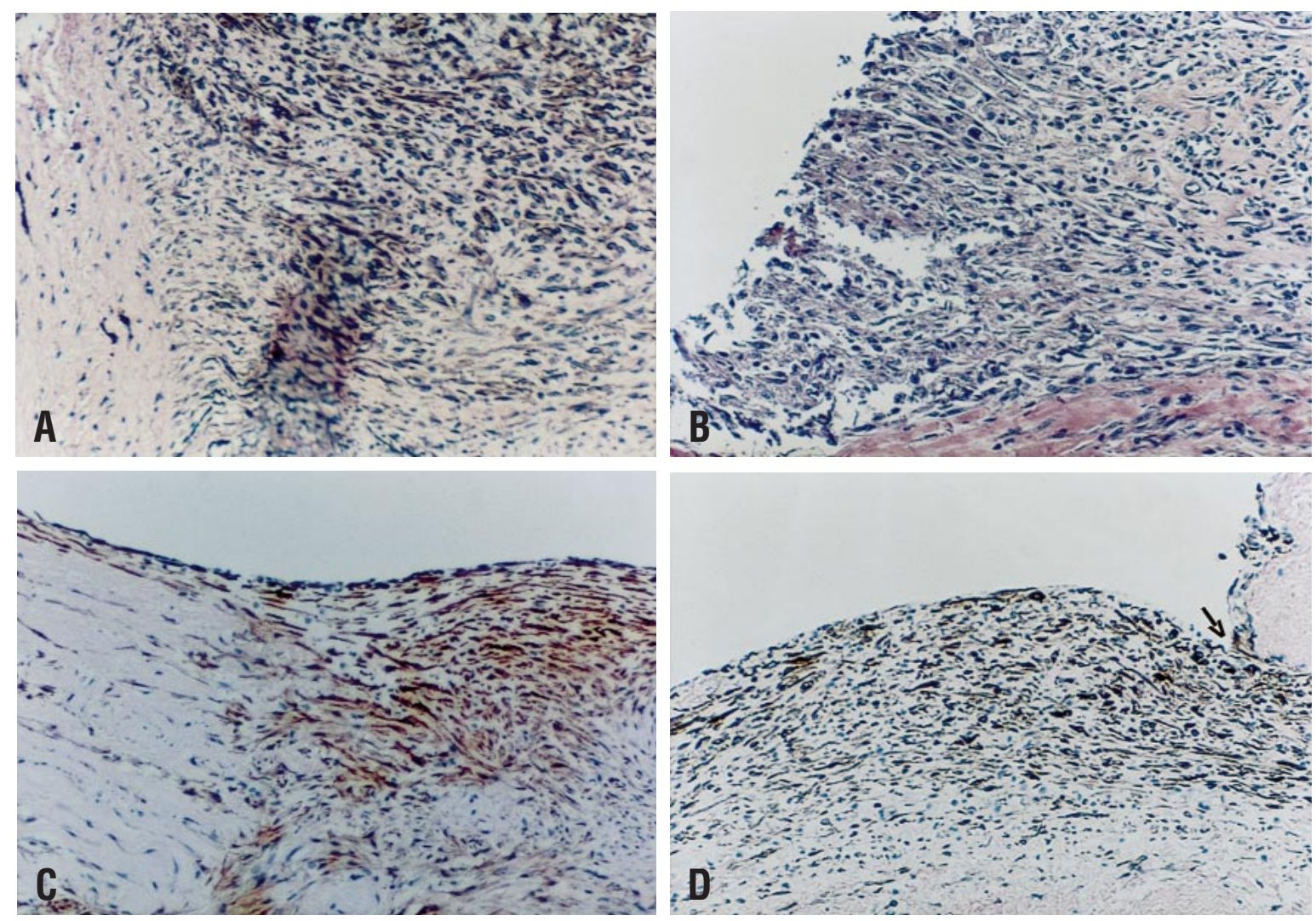

Fig 3. Multiple layers of cells expressing $\alpha$-actin were seen in the fibrin layers of the 15-day fresh patch (A) and flap (B) and the ethanol-killed patch (C) and flap (D) at the junction with the host aorta. The arrow indicates the junction of the implant and the aortic wall. Immunohistologic detection of $\alpha$-smooth muscle actin counterstained with hematoxylin and eosin (magnification $\times 100)$.

Sigma Chemical Co, St Louis, Missouri, and used according to the manufacturer's recommendations.

\section{Results}

\section{Gross observations}

Fresh pericardium. On day 5, fibrin accumulation was found on the luminal aspects of the patch and conduit as well as both surfaces of the flap. On day 10, 1 flap showed thinning with sparse fibrin deposition and the second showed thickening with heavy fibrin deposition on both surfaces. The patch and conduit appeared thickened on day 15 , but the luminal surfaces were smooth. The flap continued to thicken and appeared contracted. On day 30, the luminal aspects of the patch and conduit were smooth. There was extensive fibrosis with thickening and retraction on the flap (Fig 2, A).

Ethanol-killed pericardium. On day 5, minimal fibrin accumulation was found on the luminal aspects of the patch, conduit, and flap, which remained constant through day 10. By day 15, the patch and conduit appeared thickened but were free of clot. The flap was clean and free of fibrosis. The luminal aspects of the 30-day patch and conduit were smooth without fibrin accumulation. The ethanol-killed flap was smooth, not thickened, and free of clot (Fig 2,B).

\section{Histologic findings}

\section{Fresh}

DAY 1. Thin fibrin deposits containing polymorphonuclear leukocytes (PMNs) were seen on the luminal surface of the patch and conduit, as well as both surfaces of the flap.

DAY 5. Fibrin deposition and PMNs were present in all fresh implants with the contiguous aorta similarly affected. At all 3 sites, PMNs and spindle-shaped cells that stained weakly for $\alpha$-actin were observed near the interface between the implant and the fibrin clot.

DAY 10. The luminal surfaces of the patch and conduit showed increased fibrin deposition with cellular debris. Cells that were weakly positive for $\alpha$-actin were observed near the luminal aspect of the patch and con- 

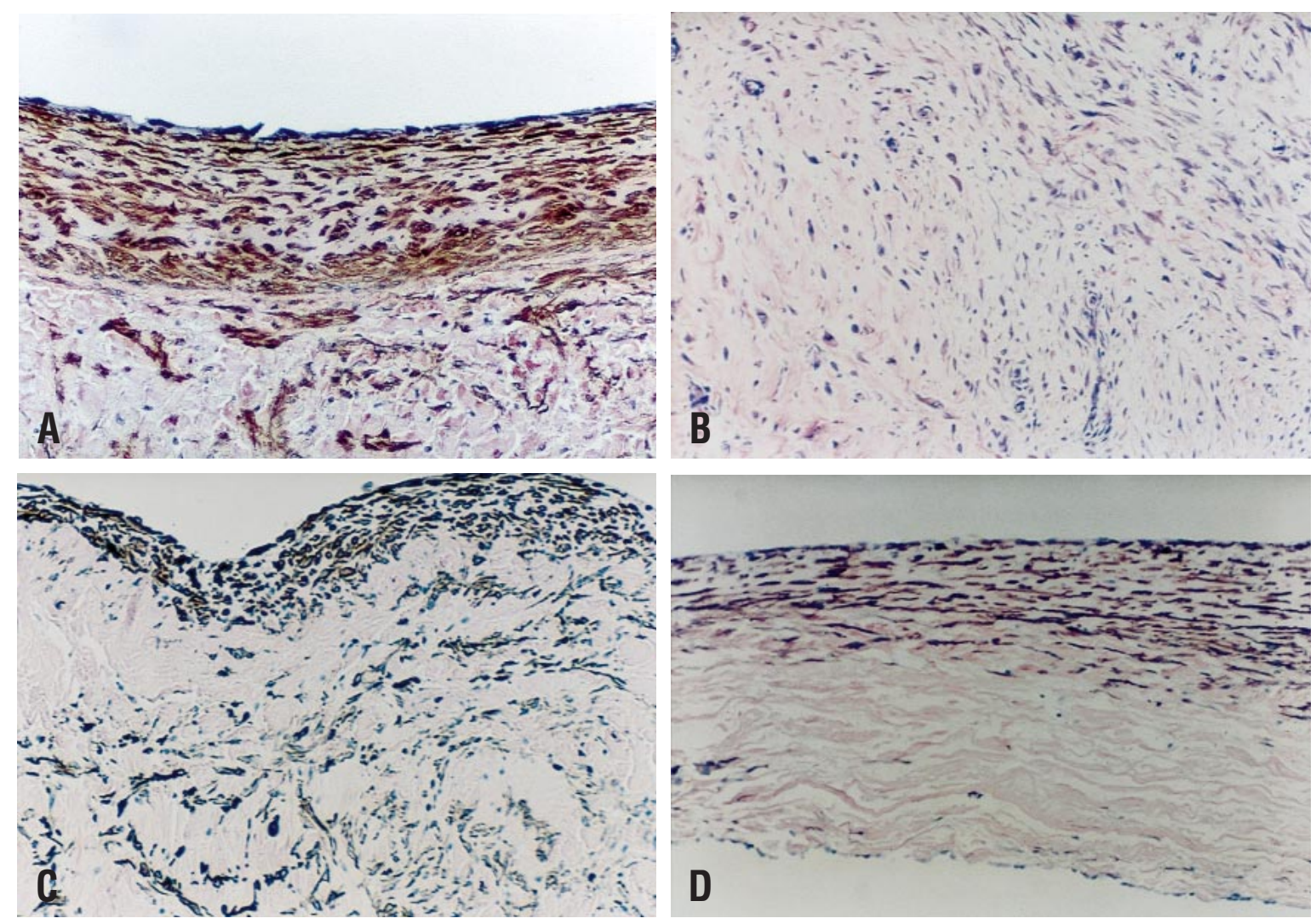

Fig 4. At 30 days, $\alpha$-actin-expressing cells extended across the entire fresh conduit (A). The fresh flap contained randomly oriented cells that stained for $\alpha$-actin with various intensities $(\mathbf{B})$. The ethanol-killed conduit $(\mathbf{C})$ and flap (D) were being repopulated by cells expressing $\alpha$-actin, presumably moving into the tissue from the host aorta. Immunohistologic detection of $\alpha$-actin, counterstained with hematoxylin and eosin (magnification $\times 100$ ).

duit oriented perpendicular to the implant surface. Several layers of cells strongly expressing $\alpha$-actin were present in the fibrin layers on the surface of the implants. A layer of cells expressing von Willebrandrelated antigen was observed on the luminal surface of the fibrin. In the flap, different layers of fibrin deposition with various degrees of cellularity were observed on both sides. More cellular activity was apparent at the interface between the implant surface and the fibrin clot than in the interior of the pericardial implant. Cells expressing von Willebrand-related antigen and $\alpha$-actin were present at the junction of the fresh flap and aortic wall, but no cells expressing von Willebrand-related antigen were present on the surface or within the implant.

DAY 15. Multiple layers of cells strongly expressing $\alpha$-actin were seen at the junctions of the host upstream aorta and the 15-day patch and conduit (Fig 3, A). Between these cells and the original implant was a layer of organized fibrin with a high degree of cellularity. A discontinuous layer of cells expressing von Willebrand-related antigen was present on the luminal surface of the implants. Trichrome staining showed that the collagen bundles within the pericardium appeared to be dispersed by cells and new matrix. In the flap, numerous cells expressing moderate levels of $\alpha$-actin were present at the fibrin-implant interface. Similar to the patch and conduit, multiple layers of $\alpha$-actin-positive cells were present at the junction between the aortic wall and the fibrin layers of the flap (Fig 3, B). No cells expressing von Willebrand-related antigen were seen on the flap. Trichrome staining indicated the collagen in the original pericardial tissue was dispersed by the deposition of new matrix.

DAY 30. The patch and conduit implants were difficult to distinguish from the surrounding aorta. The $\alpha$ actin-positive cells, also seen in the day 15 implants, extended across the entire implant (Fig 4, $A$ ) and were covered by a layer of endothelium-like cells expressing von Willebrand-related antigen (Fig 5, A). Similar to day 15 , trichrome staining revealed that newly deposited collagen separated collagen bundles of the original implants (Fig 6). While the patch and conduit were incorporated 

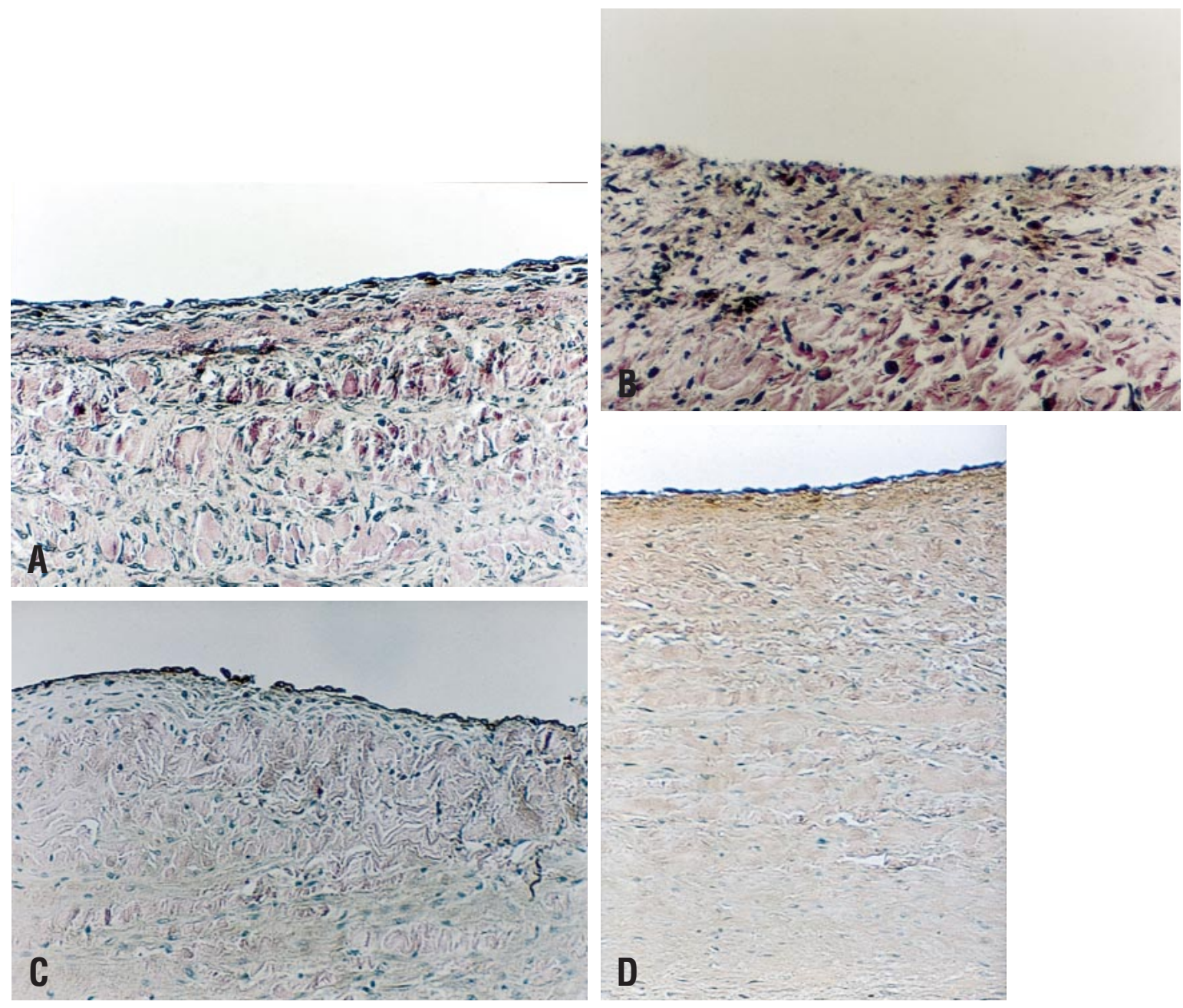

Fig 5. The 30-day fresh conduit (A) was covered by a layer of cells expressing von Willebrand-related antigen, characteristic of an endothelium. This surface layer of cells was absent on the surface of the fresh flap (B). The layer of cells expressing von Willebrand-related antigen was also present on the ethanol-killed conduit (C) and flap (D). Immunohistologic detection of von Willebrand-related antigen counterstained with hematoxylin and eosin (magnification $\times 100$ ).

into a functional structure, the flap was retracted and fibrotic. The fibrotic tissue of the flap was vascularized and contained randomly oriented cells that stained for $\alpha$ actin with various intensities (Fig 4, $B$ ). The movement of multiple layers of $\alpha$-actin-positive cells from the aortic wall onto the implant appeared to be interrupted by the deposition of new fibrin. No endothelium-like cells were present on any portion of the flap (Fig 5, B). The collagen matrix of the original flap implant was difficult to identify by trichrome staining.

\section{Ethanol-killed pericardium}

DAYS 1 AND 5. PMNs and clot were present on the surfaces of the ethanol-killed patch, conduit, and flap. By day 5 , the implants appeared the same as on day 1 , except that there was a noticeable reduction of the amount of clot. No vital cells were observed in the implants before day 5 , indicating that $50 \%$ ethanol was effective in killing all the cells in the autologous implants (Fig 7).

DAY 10. The patch and conduit had a thin fibrin layer containing PMNs with no new fibrin deposition. There were $\alpha$-actin-expressing cells in the thin fibrin layer of the luminal side of the implant close to the aortic wall. Cells expressing von Willebrand-related antigen were present on the luminal surface of the implants but had not formed a continuous monolayer.

No new fibrin deposition was seen on the ethanolkilled flap. Cells positive for $\alpha$-actin were present at the 


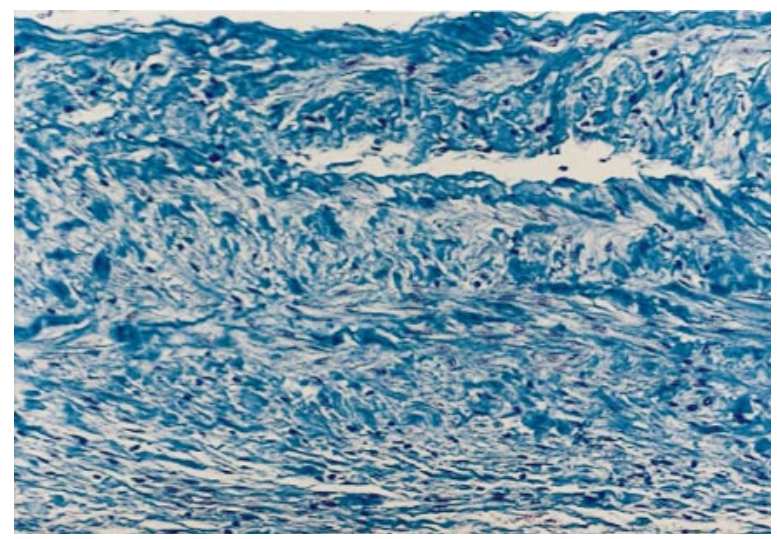

Fig 6. Trichrome staining of the 30-day fresh patch indicated that the collagen of the original implant was separated by the deposition of new matrix (magnification $\times 100$ ).

junction of the aortic wall and implant. An occasional cell staining positive for von Willebrand-related antigen was seen on both luminal sides of the implant.

DAY 15. The patch and conduit contained multiple layers of spindled-shaped $\alpha$-actin-positive cells within the remodeled fibrin with few cells seen within the original implant (Fig 3,C). A discontinuous layer of cells expressing von Willebrand-related antigen was also present on the luminal surface of the implants. Trichrome staining showed the collagen bundles of the original implant to be separated by new matrix.

A thin fibrin layer was present on the flap with no new fibrin deposition. The fibrin layer had been remodeled and contained cells, but the implant itself had very few cells. Cells strongly expressing $\alpha$-actin bridged from the aortic wall into the fibrin layer of the implant (Fig 3, D). A layer of cells expressing von Willebrandrelated antigen was beginning to cover the implant. Trichrome staining revealed that new collagen was produced at the junction of the implant and aorta and within the fibrin layer.

DAY 30. The luminal surface of the patch and conduit had multiple layers of spindle-shaped $\alpha$-actin-positive cells (Fig 4, C) with a continuous surface layer of cells expressing von Willebrand-related antigen (Fig 5, C). Cells were present within the implant, and trichrome staining showed remodeled fibrin with new collagen deposition. The ethanol-killed flap was repopulated by a multilayer of spindle-shaped $\alpha$-actin-expressing cells that presumably came from the aortic wall (Fig 4, D). In contrast to the fresh flap implant, there was a continuous layer of cells expressing von Willebrand-related antigen on both surfaces of the ethanol-killed flap implant (Fig 5, D). Trichrome staining showed the surface fibrin was replaced by collagen.

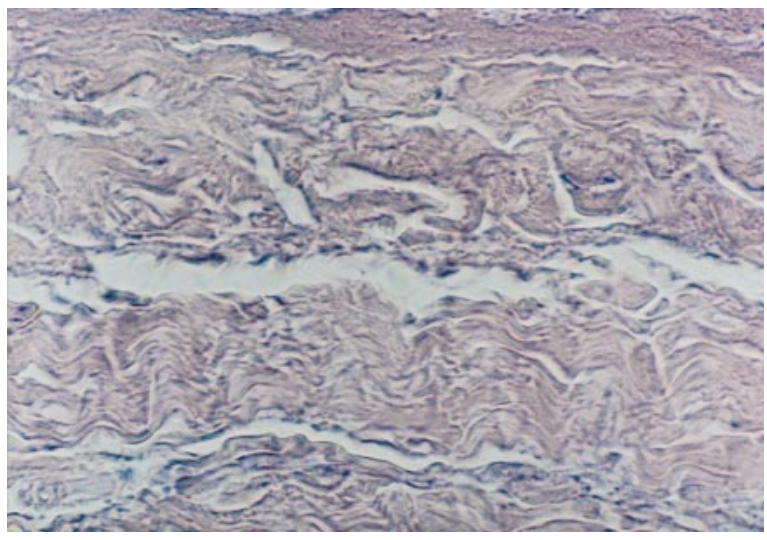

Fig 7. No vital cells were seen internal to the original pericardium after ethanol treatment. Day 5 ethanol-killed flap stained with hematoxylin and eosin (magnification $\times 100$ ).

\section{Discussion}

The use of fresh autologous pericardium as a cardiovascular implant has been reported with mixed results. The transplants have been shown to become fibrotic and retracted, ${ }^{7,8}$ exhibit progressive thinning with dilatation and aneurysm, $, 5,9,10$ or were incorporated into the surrounding host tissue with growth potential. ${ }^{3-6} \mathrm{~A}$ common feature was tissue thinning with reduction in connective tissue cells or degenerative nucleic changes. The native collagenous tissue has been shown to undergo eventual disorganization and fragmentation.

The current study was designed in 2 parts. The fresh group provided a picture of the variability of host responses to identical, nonantigenic and viable tissue implanted in the same location but with different configurations. The ethanol-killed group was studied to alleviate the activation of cell types intrinsic to the fresh tissue, which may be responsible for the fibrotic reactions seen in the fresh flap. This experiment was performed to determine whether autologous pericardium transplants, devoid of vital cells, would resist fibrosis in the sheep, a model used in many preclinical studies of cardiovascular implants.

Histologic and immunohistologic examination of the recovered fresh implants indicated that the initial events of the host and the cells in the implants were similar. However, the outcomes of the implants were clearly different. In the fresh patch and conduit, a discontinuous layer of cells expressing von Willebrandrelated antigen, was present on the surface of the implants covering several layers of $\alpha$-actin-positive cells. Once these multiple layers of cells were established on the implant, there was no new fibrin deposition. In contrast, the fresh flap had a continuous deposition of new fibrin, which seemed to block movement 
of cells from the aortic wall into the implant. The cells present within the implant expressed $\alpha$-actin and remained randomly oriented. It is likely that the activation of these cells was responsible for the contraction and distortion of the original flap implant. No cells expressing von Willebrand-related antigen were present at any time on the surface of the flap.

Comparison of the fresh and ethanol-killed pericardial implants showed significantly different results, particularly with respect to the flap. The ethanol-killed tissue allowed for ordered recolonization of the implant, formation of a surface layer of cells expressing von Willebrand-related antigen, characteristic of an endothelium, and completely alleviated the fibrosis seen in the fresh flap. Whether these differences are due to the absence of living cells or to the extraction of factors from the pericardium is not known.

In our study, $50 \%$ ethanol treatment for 5 minutes effectively killed all intrinsic cells, as indicated by the absence of vital cells in recovered implants at early time points. Ethanol treatment for 5 minutes was adequate to penetrate the pericardium without causing the tissue shrinkage seen with higher concentrations of ethanol. Recent studies indicated that $80 \%$ ethanol may change the structure of the tissue. ${ }^{17,18}$ We have not found evidence that $50 \%$ ethanol significantly alters tissue structure.

These findings open a new field of possible clinical applications for the use of freshly obtained autologous pericardium treated with ethanol, particularly as an alternative material for valve reconstruction. Additional experimentation is needed to better understand the development of fibrosis observed with fresh autologous pericardial implants. Larger sample numbers, more frequent time points, and growth factor studies may allow for identification of the initial stages of fibrosis. In addition, long-term and calcium content studies need to be performed to ensure the stability of ethanol-killed implants. This laboratory is currently devising methods to isolate fresh and ethanol-killed pericardial flap implants from the aortic wall to prevent fibrotic contributions from host cells.

We thank to Cecilia Pang for all of her excellent work in doing the sectioning, hematoxylin and eosin, and Masson's trichrome staining of sections used in this study. We also thank the crew at the animal laboratory of the University of Montana for their assistance.

\section{REFERENCES}

1. Duran CG, Gometza B. New uses of pericardium for valve surgery. In: D'Alessandro LC, editor. Heart surgery. Rome: Casa Editrice Scientifica Internazionale; 1993. p. 69-82.
2. Piehler JM, Danielson GK, Pluth JR, Orszulak TA, Puga FJ, Schaff HV, et al. Enlargement of the aortic root or annulus with autogenous pericardial patch during aortic valve replacement: long-term follow-up. J Thorac Cardiovasc Surg 1983;86:350-8.

3. Hvass U, Pansard Y, Bohm G, Depoix JP, Engeurrand D, Worms AM. Bicaval pulmonary connection in tricuspid atresia using an extracardiac tube of autologous pediculated pericardium to bridge inferior vena cava. Eur J Cardiothorac Surg 1992;6:49-51.

4. Hvass U, Khoury W, Pansard Y, Videcoq M. Repair of pulmonary artery branches with broadly based autologous pericardial flaps. J Thorac Cardiovasc Surg 1988;95:738-40.

5. Leplay D, Hausmann PF, Wiesel W. The fate of pericardial pedicled grafts used in a fixed position in various chambers of the dog heart. J Thorac Surg 1959;37:711-9.

6. Guyton RA, Dorsey LM, Silberman MS, Hawkins HK, Williams WH, Hatcher CR Jr. The broadly based pericardial flap: a tissue for atrial wall replacement that grows. J Thorac Cardiovasc Surg 1984;87:619-25.

7. Bortolotti U, Gallo JI, Gabbay S, Factor SM, Sisto D, Frater RW. Replacement of mitral valve chordae with autologous pericardium in dogs. Thorac Cardiovasc Surg 1984;32:15-7.

8. Kumar SP, Prabahkar G, Kumar M, Kumar N, Shahid M, Ali ML, et al. Comparison of fresh and glutaraldehyde-treated autologous stented pericardium as pulmonary valve replacement. J Card Surg 1995; 10:545-51

9. Kawashima Y, Nakano S, Kato M, Danno M, Sato K. Fate of pericardium utilized for the closure of ventricular septal defect: postoperative ventricular septal aneurysm. J Thorac Cardiovasc Surg 1974;68:209-18.

10. Rosenthal A, Gross RE, Pasternac A. Aneurysms of right ventricular outflow patches. J Thorac Cardiovasc Surg 1972;63:735-40.

11. Sauvage LR, Wood SJ, Bill AH, Logan GA. Pericardial autografts in the mitral valve: a preliminary report. J Thorac Cardiovasc Surg 1962;44:67-72.

12. Frater RWM, Berghuis J, Brown AL Jr, Ellis FH Jr. Autogenous pericardium for posterior mitral leaflet replacement. Surgery 1963;54:260-9.

13. Seybold-Epting W, Chiariello L, Hallman GL, Cooley DA. Aneurysm of pericardial right ventricular outflow tract patches. Ann Thorac Surg 1977;24:237-40.

14. Morris JH, McNamara DG. Residual sequelae and complications of surgery for congenital heart disease. Prog Cardiovasc Dis 1975;18:1-25

15. Hjelms E, Pohlner P, Barratt-Boyes BG, Gavin JB. Study of autologous pericardial patch grafts in the right ventricular outflow tracts in growing and adult dogs. J Thorac Cardiovasc Surg 1981;81:120-3.

16. Piehler JM, Danielson GK, McGoon DC, Wallace RB, Fulton RE, Mair DD. Management of pulmonary atresia with ventricular septal defect and hypoplastic pulmonary arteries by right ventricular outflow obstruction. J Thorac Cardiovasc Surg 1980;80: $552-67$.

17. Vyavahare N, Hirsch D, Lerner E, Baskin JZ, Schoen FJ, Bianco $\mathrm{R}$, et al. Prevention of bioprosthetic heart valve calcification by ethanol preincubation: efficacy and mechanisms. Circulation 1997;95:479-88.

18. Vyavahare NR, Hirsch D, Lerner E, Baskin JZ, Zand R, Schoen FJ, et al. Prevention of calcification of glutaraldehyde-crosslinked porcine aortic cusps by ethanol preincubation: mechanistic studies of protein structure and water-biomaterial relationships. J Biomed Mater Res 1998;40:577-85. 